\title{
Serum prolactin in patients with relapsing remitting multiple sclerosis
}

\author{
Hoda A. Alwakil', Ayman M. Al-Malt ${ }^{1}$, Osama A. Ragab ${ }^{1 *}$ D, Muhammed T. Abdel Ghafar ${ }^{2}$ and Elsayed A. Tageldin ${ }^{1}$
}

\begin{abstract}
Background: Multiple sclerosis (MS) is an inflammatory demyelinating disorder that affects the central nervous system (CNS) of females more than males. The objective of the current study was to assess serum level of prolactin (PRL) and tumor necrosis factor alpha (TNFa) in patients with relapsing remitting multiple sclerosis (RRMS) and to explore their role in disease activity.

Subjects and methods: Fifty females were included in this study, 40 patients with RRMS were evaluated during relapse and remission and 10 age-matched healthy subjects who served as controls. All patients were subjected to neurological evaluation including Expanded Disability Status Scale (EDSS), brain, and spine magnetic resonance image (MRI); serum PRL and TNFa levels were measured for all patients (during relapse and remission) and controls.

Results: Median serum PRL level was significantly higher in MS patients during relapse than remission and control subjects $(P=0.041)$. TNFa level was significantly higher in MS patients in relapse than remission $(P=0.026)$ as well as the healthy controls $(P=0.001)$. The area under the receiver operating characteristic curve (AUROC) was analyzed for prediction of MS relapse, AUROC of serum TNFa was 0.811 and that of serum PRL was 0.678. Both serum PRL and TNFa were positively correlated in MS patients in relapse with each other $(r=0.672, P<0.001)$ and also with age, EDSS, number of relapses, and MRI lesion number $(P$ value $=0.001)$.
\end{abstract}

Conclusion: Elevated serum PRL and TNFa levels are associated with relapse in MS patients. Moreover, they are positively correlated with EDSS, disease duration, and MRI lesion number.

Keywords: Multiple sclerosis, Serum PRL, Serum TNFa, EDSS, MRI lesion number

\section{Introduction}

Multiple sclerosis (MS) is a chronic autoimmune disorder of the central nervous system (CNS). Its etiology is not completely known but evidences suggested a complex interaction between genetic, environmental [1], and hormonal factors [2]. MS affects females more than males with ratio of 3:1 [3]. The Pregnancy in Multiple Sclerosis (PRIMS) study showed that MS relapse rates increase in the first 3 months postpartum [4], which is thought to be driven by rapid drop of estrogen and progesterone levels and the elevated levels of hormones involved in breastfeeding during that period [3].

\footnotetext{
* Correspondence: osama.ragab@med.tanta.edu.eg

${ }^{1}$ Neurology Department, Tanta University, Tanta 31527, Egypt

Full list of author information is available at the end of the article
}

PRL is secreted by the anterior pituitary and extrapituitary tissues including $\mathrm{T}$ and $\mathrm{B}$ lymphocytes and possess both anti-inflammatory as well as pro-inflammatory properties [5]. Human PRL gene is located on the short arm of chromosome 6, near the HLADRB1 region and tumor necrosis factor alpha (TNF $\alpha$ ) which are involved in PRL gene expression [6].

The HLADRB1 and TNF $\alpha$ have been associated with the MS pathogenesis, while the role of PRL has been controversial. On one hand, PRL can have neuroprotective benefits, while on the other hand, it is thought to have pro-inflammatory effects that may exacerbate MS [7].

PRL is secreted by the anterior pituitary gland under tonic dopaminergic hypothalamic inhibition. The cytokines interleukin 1 (IL-1), interleukin 6 (IL-6), and

\section{Springer Open}

(c) The Author(s). 2020 Open Access This article is licensed under a Creative Commons Attribution 4.0 International License, which permits use, sharing, adaptation, distribution and reproduction in any medium or format, as long as you give appropriate credit to the original author(s) and the source, provide a link to the Creative Commons licence, and indicate if changes were made. The images or other third party material in this article are included in the article's Creative Commons licence, unless indicated otherwise in a credit line to the material. If material is not included in the article's Creative Commons licence and your intended use is not permitted by statutory regulation or exceeds the permitted use, you will need to obtain permission directly from the copyright holder. To view a copy of this licence, visit http://creativecommons.org/licenses/by/4.0/. 
interleukin 2 (IL-2) stimulate its secretion, while interferon $\gamma$ (INFY) and endothelin-3 inhibit PRL release [8].

PRL has a key role in both innate and adaptive immunological responses, via regulating the development of CD4- CD8 - thymocytes into CD4+ CD8+ T cells [5]. Hyperprolactinemia intervenes with the development of B cell tolerance through hampering B cell clonal deletion and lessening the activation threshold of anergic B cells. Also, PRL facilitates the development of antigenpresenting cells expressing co-stimulatory molecules CD40 and MHC class II [9].

The relationship between HLA-DRB1, TNF $\alpha$, and PRL gene has been documented in females with autoimmune disorders, suggesting their possible interaction in the pathogenesis of these disorders. Evidences suggested that TNF $\alpha$ can increase pituitary PRL release by stimulating the hypothalamus specifically during disease activity [10].

TNF $\alpha$ can trigger both cell death or survival pathways depending on the pathophysiological conditions. In MS, it exerts a dual role on the linkage with its receptors either tumor necrosis factor-alpha receptors 1 (TNFR1) or 2 (TNFR2). Its neurodegenerative effects are mediated by TNFR1, while TNFR2 mediates the neuroprotective effects [11].

In this study, we aimed to assess the serum level of PRL and TNFo in patients with relapsing remitting MS (RRMS) and to verify their role in disease activity.

\section{Subjects and methods}

This is a hospital-based prospective study carried out at Neuropsychiatry Department, Tanta University Hospitals throughout a 12-month period, started from June 2018. The study protocol was approved by the ethical committee in Tanta University, Egypt, under the code number (3226/ 04/18) on April 2018. Participation was voluntary and all contributors received detailed information about the aims of this research work and an informed written consent was obtained prior to the commencement of the study.

Forty female patients with RRMS aged from 20 to 45 years old fulfilling McDonald criteria of MS 2017 [12], without a history of receiving disease-modifying therapy in addition to 10 age-matched healthy females were included in the study who served as a control group.

Patients with other autoimmune disorders, primary or secondary progressive MS, breastfeeding patients, and patients receiving medications that affect the hormonal status (antipsychotics, antiemetic, or antidepressants) were excluded from the study.

All patients were subjected to the following: history taking (age, disease duration, number of relapse and full past, and current medical history) general, neurological examination, and assessment by Expanded Disability Status Scale (EDSS) [13]. A relapse was defined as an increase of two points in one or more Kurtzke Functional
Systems, or an increase of one point in two or more KFS (except changes in bowel or bladder function or cognition), in the absence of fever, lasting for at least $24 \mathrm{~h}$, preceded by at least 30 days of clinical stability or improvement. Remission considered on return to base line score [14].

Magnetic resonance image (MRI) of the brain and spinal cord were carried out for all patients using Magnetom Sempra 1.5 Tesla, Siemens, Germany, to detect site, size, and number of MS plaques and to exclude other structural lesions. The MRI examination included axial T1-weighted sequences as well as T2-weighted dual fast spin echo sequence and a FLAIR sequence. Axial and coronal T1-weighted sequences were acquired $6 \mathrm{~min}$ after intravenous injection of $0.1 \mathrm{mmol} / \mathrm{kg}$ gadolinium chelate $\left(\right.$ Omniscan $\left.{ }^{(\mathrm{R})}\right)$.

\section{Laboratory assessment}

Serum levels of PRL and TNF $\alpha$ were measured for all patients (during the relapse phase before steroid pulse therapy administration, then during the remission phase) and control subjects included in this study. Serum PRL was estimated mainly during the follicular phase of the menstrual cycle $[15,16]$. This was performed at Unit of Clinical Chemistry, Clinical Pathology Department, Tanta University. Peripheral blood samples were collected without anticoagulant. All of the samples were immediately centrifuged at $3000 \mathrm{rpm}$ for $15 \mathrm{~min}$, and the sera aliquots were stored in $-20^{\circ} \mathrm{C}$ for TNF $\alpha$ and PRL estimation. Serum PRL level was measured by immunofluorescence techniques on AIA 1800, Tosoh Bioscience, Tokyo, Japan. TNF $\alpha$ level in the serum was estimated by ELISA double antibody sandwich technique using BT LAB, Shanghai Crystal Day Biotech CO., LTD. Shanghai, China, Cat.no: E0082Hu. The assay was performed following the manufacturer's instructions and the developed color was measured at $450 \mathrm{~nm}$ on a Tecan Spectra II microplate reader (Switzerland). The results were calculated from the standard curve. The sensitivity was $1.52 \mathrm{pg} / \mathrm{ml}$, the intra-assay CV was $<10 \%$, and the interassay CV was $<12 \%$.

\section{Statistical analysis}

The collected data were organized, tabulated, and statistically analyzed by SPSS version 19, 2011 created by IBM, Illinois, Chicago, USA. Parametric numerical data were expressed as mean and standard deviation and compared among the groups using ANOVA test and Tukey post hoc test. Non-parametric data were expressed as median and range and compared among the studied groups using the Kruskal-Wallis test. The performance characteristics of serum PRL and TNF $\alpha$ were assessed by AUROC analysis and their optimal cutoff was determined via Youden index. Serum PRL and 
TNF $\alpha$ were correlated with the studied parameter using Pearson correlation. For all statistical tests done, the threshold of significance was fixed at $5 \%$ level ( $P$ value), i.e., when $<0.05$ significant results are indicated.

\section{Results}

The mean age of the studied patients in years was 34.10 \pm 7.18 and for controls was $34.90+6.51$. There was no statistically significant difference between patients and controls regarding age $(P=0.920)$. The duration of illness in patient group was $6.20 \pm 3.63$ years, while the total number of relapses was $2.27 \pm 0.98$, while the EDSS was $2.62 \pm 1.59$.

The median serum PRL level was significantly higher in MS patients during relapse $(12.5 \mathrm{ng} / \mathrm{ml})$ than those during the remission periods $(9.6 \mathrm{ng} / \mathrm{ml})(P=0.023)$. There was no statistically significant difference between patients in relapse and healthy controls regarding serum PRL level $(P=0.792)$ (Table 1, Fig. 1).

There was a significantly high level of serum TNFo in MS patients in relapse compared to MS patients in remission $(P=0.026)$ as well as to healthy controls $(P=$ $0.001)$. There was no statistically significant difference in serum TNF $\alpha$ level between MS patients in remission and healthy controls $(P=0.107)$ (Table 1 , Fig. 2).

ROC curve analysis was performed and the performance characteristics of serum PRL and TNF $\alpha$ were presented in Fig. 3. Youden index was used to determine the optimal cutoff value that achieves the highest sensitivity and specificity. The AUROC of serum PRL was 0.647 and the optimal cutoff was $>10.0 \mathrm{ng} / \mathrm{ml}$ (sensitivity of $65.0 \%$ and specificity of $42.5 \%$ ), whereas the AUROC of TNF $\alpha$ was 0.645 and the optimal cutoff was $>49.1 \mathrm{pg} / \mathrm{ml}$ (sensitivity of $55.0 \%$ and specificity of $52.5 \%)$ for differentiating the patients with MS relapse from those with remission. For differentiating the patients with MS relapse from the healthy controls, the AUROC of serum PRL was 0.678 and the optimal cutoff was $>9.1 \mathrm{ng} / \mathrm{ml}$ (sensitivity of $85.0 \%$ and specificity of 45.5\%), whereas the AUROC of TNF $\alpha$ was 0.811 and the optimal cutoff was $>40.1 \mathrm{pg} / \mathrm{ml}$ (sensitivity of $80.0 \%$ and specificity of $72.7 \%)$.

There was a significant positive correlation of serum PRL with age $(P=0.049)$, number of relapses $(P=$ $0.003)$, EDSS $(P=0.001)$, and MRI lesion number $(P<$ 0.001) (Fig. 4a-e). Serum TNF $\alpha$ had a statistically significant positive relation with age $(P=0.023)$, number of relapses $(P=0.023)$, EDSS $(P=0.025)$, and MRI lesion number $(P<0.001)$ (Fig. $4 \mathrm{f}-\mathrm{j})$. A significant positive correlation was found between serum PRL and TNFa in MS patients in relapse $(r=0.672, P<0.001)$ (Fig. 4k).

\section{Discussion}

PRL and TNF $\alpha$ were investigated in MS patient in order to explore their possible role in the disease pathogenesis. However, there was no clear conclusion regarding their relation to disease activities [17-19]. Our study objective was to assess PRL and TNF $\alpha$ serum levels in RRMS patients in addition to explore their potential role in MS disease activity.

In the current study, patients with RRMS had elevated median PRL levels during relapse period in comparison to the remission period. For differentiating the patients with MS relapse from those with remission and the healthy controls, AUROCs of serum PRL were 0.647 and 0.678 respectively. Serum PRL had statistically significant positive correlations with age, EDSS, MRI lesion number, and number of relapses in MS patients. Our results were similar to the previous work of Belal and colleagues [20] who reported no statistically significant difference between patients with MS and healthy subjects regarding PRL levels, and proposed that PRL levels have no relation with the phenotype of MS.

In our study, serum TNF $\alpha$ level was significantly elevated in MS patients during relapse compared to remission state. On the other hand, there were no differences between MS patients during the remission phase and healthy female regarding serum TNF $\alpha$ level. For differentiating the patients with MS relapse from those with remission and the healthy controls, AUROCs of serum TNF $\alpha$ were 0.645 and 0.811 respectively. Serum TNF $\alpha$ had statistically significant positive correlations with age, EDSS, MRI lesion number, and number of relapses in MS patients in relapse. Both serum PRL and TNF $\alpha$ level were correlated with each other. Our finding may give a clue to the link between cytokines and PRL interaction.

Grinsted and colleagues' previous research in 1989 [21] showed substantially elevated levels of PRLs in the serum of 14 MS female patients compared to controls. Similarly, Awerbuch and Sandyk [22] found elevated serum PRL levels in patients with MS. Their work did not confirm any correlation between serum PRL levels and MS disease duration among their studied cohort.

Table 1 Comparison of serum PRL and TNFa among the studied groups

\begin{tabular}{lllll}
\hline & MS patients in relapse & MS patients in remission & Control subjects & $P$ value \\
\hline Median serum PRL $(\mathrm{ng} / \mathrm{ml})$ & $12.5(5.4-39.9)^{\mathrm{a}}$ & $9.6(4.3-23.9)$ & $11.45(4.1-24.0)$ & $0.041^{*}$ \\
Serum TNFa $($ mean $\pm \mathrm{SD})(\mathrm{pg} / \mathrm{ml})$ & $59.77 \pm 21.27^{\mathrm{ab}}(28.6-102.7)$ & $48.79 \pm 14.55(29.1-88.1)$ & $37.87 \pm 14.02(21.6-62.3)$ & $0.001^{*}$ \\
\hline
\end{tabular}

${ }^{\text {a }}$ Significant $P$ value (MS patients in relapse vs MS patients in remission)

${ }^{\mathrm{b}}$ Significant $P$ value (MS patients in relapse vs control subjects MS multiple sclerosis, PRL prolactin, TNFa tumor necrosis factor alpha) 


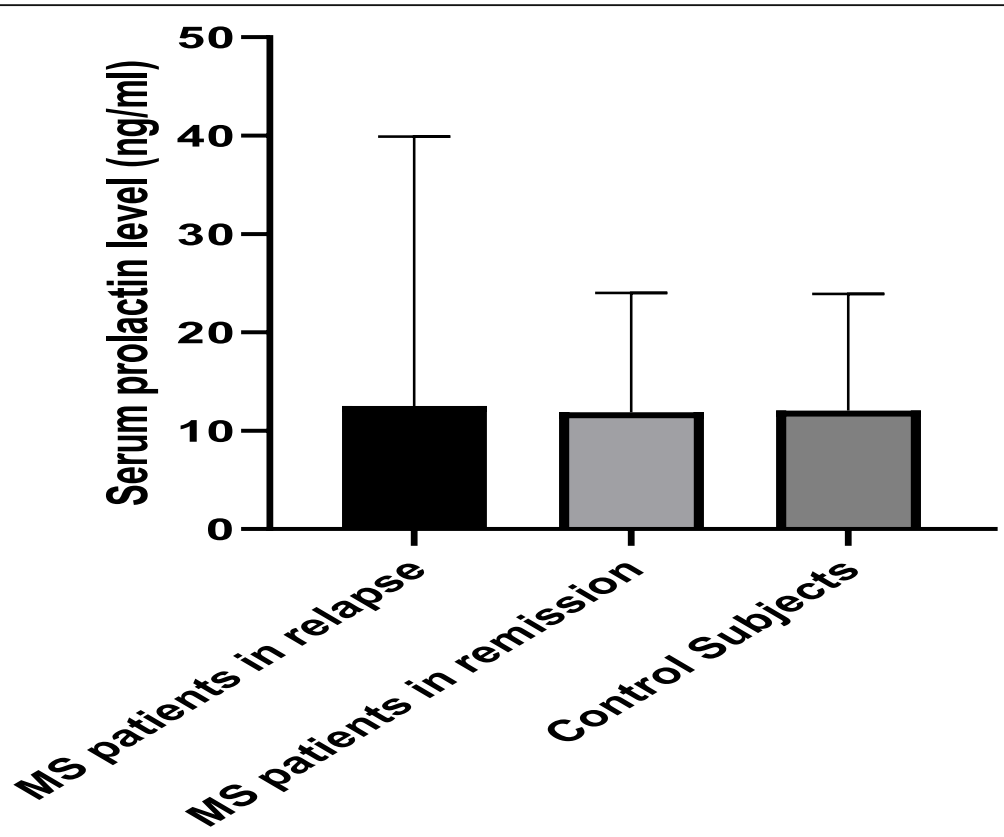

Fig. 1 Comparison of serum prolactin (PRL) level among the studied groups

An interesting study compared Asian and Western MS patients revealed that serum PRL levels are significantly elevated in Asian patients [23]. Another study found elevated serum and cerebrospinal fluid PRL level in female patients with RRMS, while male patients had normal PRL levels [24]. This finding could be suggestive of a sexually dimorphic response to CNS injury; also, it can explain the high prevalence of MS in females and their good prognosis relative to male patients. These two studies show the racial and gender effect on PRL secretion and its role in MS.
The dual role of PRL in MS immune pathogenesis was further confirmed by two studies; the first one was done by Correale and colleagues 2014 [25], who studied the role of PRL in MS patients and its effect on B lymphocytes; they reported that PRL induces CD40 expression in B cells and promotes B cell autoreactivity in MS. The second one was conducted by De Giglio and colleagues [16] who studied the relationship between PRL plasma levels and brain damage; they concluded that PRL may potentiate myelin repair. Another study by Gregg [26] reported that PRL signaling plays a role in generation of

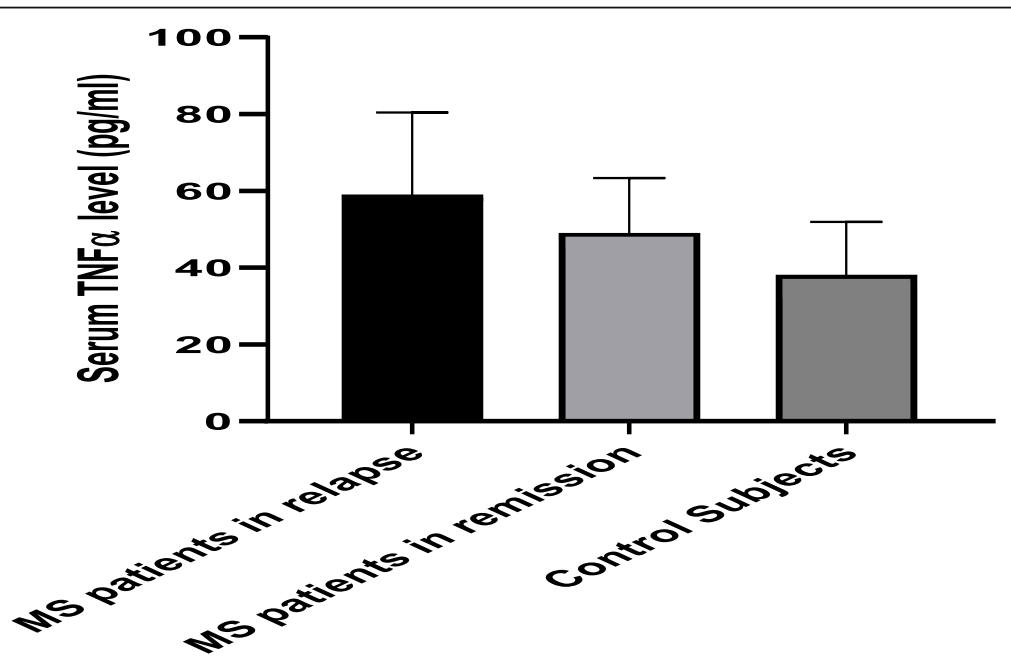

Fig. 2 Comparison of serum tumor necrosis factor alpha (TNFa) level among the studied groups 


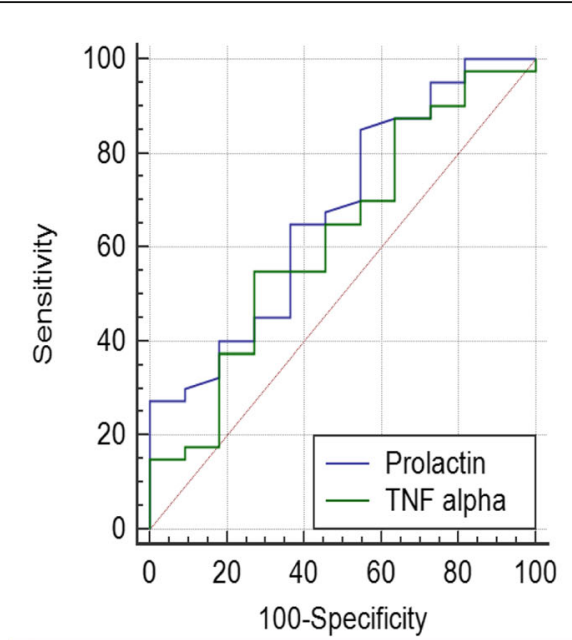

A

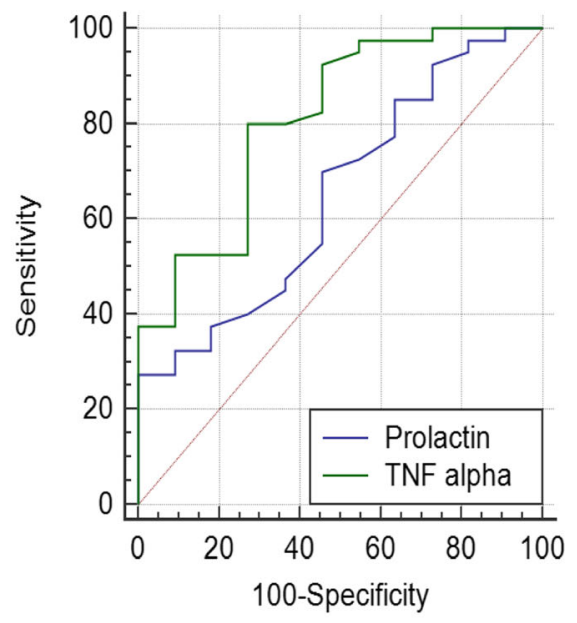

B

Fig. 3 AUROC analysis of the performance characteristics of serum PRL and TNFa in patients with MS relapse versus a patients with MS remission and $\mathbf{b}$ healthy controls
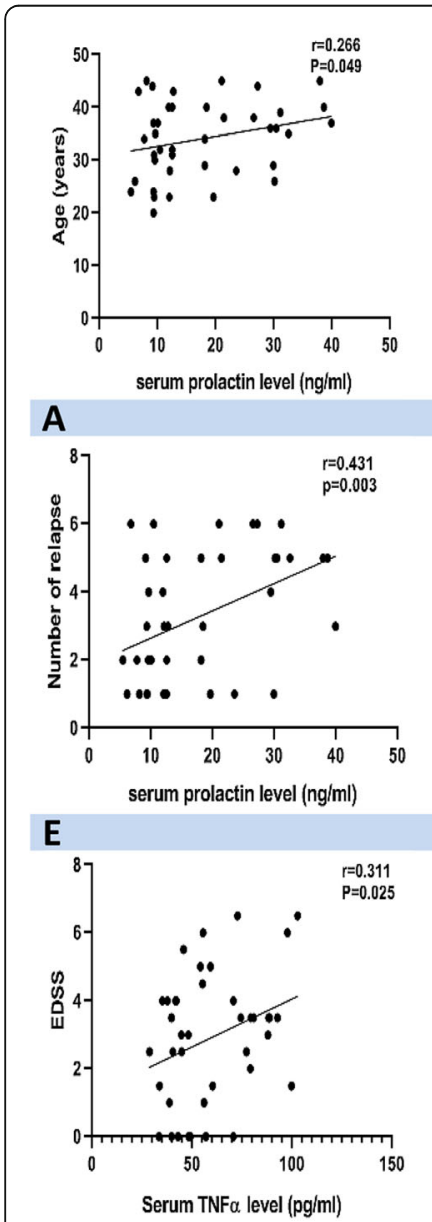

I

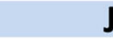
of serum TNFa in MS patients in relapse with $\mathbf{f}$ age, $\mathbf{g}$ duration of illness, $\mathbf{h}$ MRI lesion number, $\mathbf{i}$ EDSS, and $\mathbf{j}$ number of relapse. $\mathbf{k}$ Correlation of serum PRL with serum TNFa in MS patients in relapse

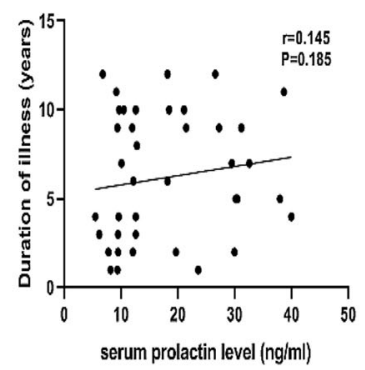

B

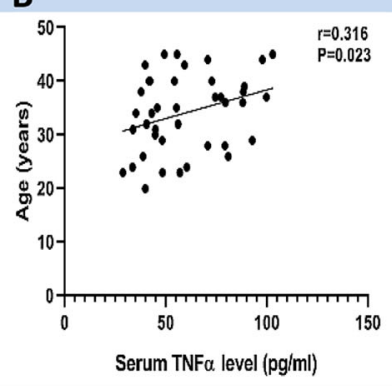

$\mathbf{F}$

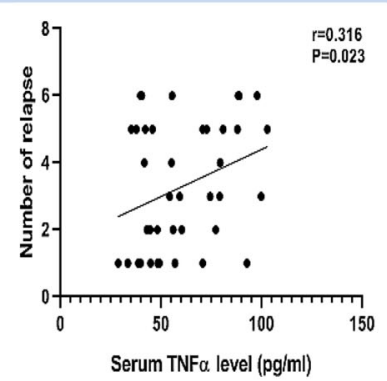

J

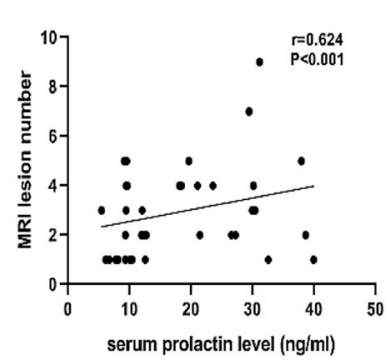

C

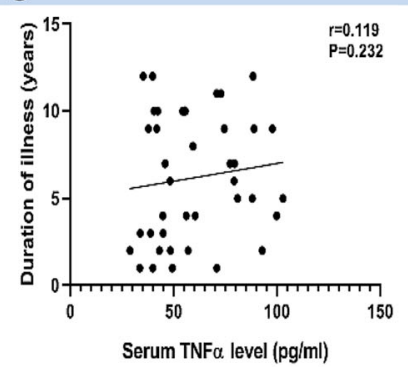

G

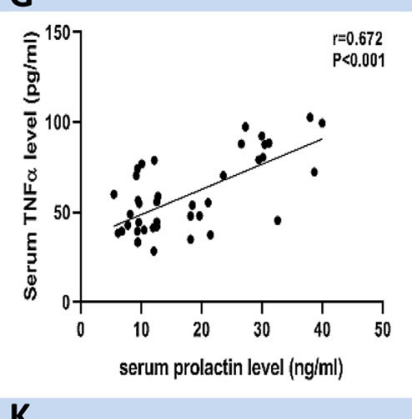

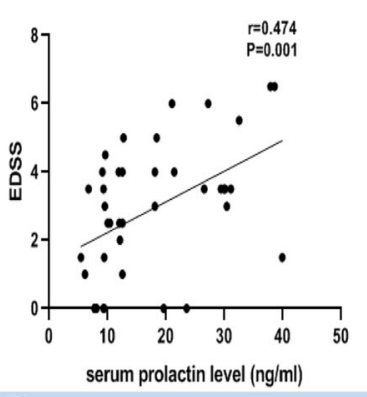

D

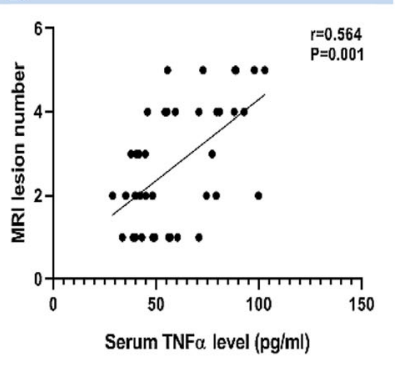

H 
new oligodendrocytes in the maternal central nervous system.

From a therapeutic perspective, the dual nature of this hormone suggests great caution when trying to manipulate PRL levels in MS, as it has been postulated that increasing systemic PRL levels improve remyelination and neuronal survival in animal models of multiple sclerosis (MS), but it has been suggested that this therapeutic strategy may also increase inflammatory responses and potentially harm patients [27]. TNF- $\alpha$-targeting immunebiologicals are extremely successful in treating a number of immune-mediated diseases; however, clinical trials using anti-TNF- $\alpha$ monoclonal antibodies as therapy in MS patients resulted in disease exacerbation [28].

Finally, we need more extensive research to explore the complex interactions of PRL, immune system, and CNS autoimmune disorders.

\section{Conclusion}

Both serum PRL and TNF $\alpha$ level are significantly higher in patients with RR MS during relapse than during remission and positively correlated EDSS, MRI lesion number, and number of relapses.

\section{Recommendations}

Further studies are needed to clarify the mechanisms behind a possible role of PRL in MS and to explore the orchestrated interaction of PRL, immune system, and CNS.

\section{Limitations}

The study is only on RRMS patients and only on females at childbearing period and the limited number of patients. And limited number of control subjects as recruiting healthy female and ask them for blood sample at 8 am during the follicular phase of their menstrual cycle was very difficult. The long duration of disease course in some patients without receiving DMT was due to initial misdiagnosis.

\section{Abbreviations \\ MS: Multiple sclerosis; CNS: Central nervous system; PRL: Prolactin TNFa: Tumor necrosis factor alpha; PRISM: The Pregnancy in Multiple Sclerosis; RRMS: Relapsing remitting multiple sclerosis; EDSS: Expanded Disability Status Scale; MRI: Magnetic resonance image; IL: Interleukin}

\section{Acknowledgements}

We wish to express our great appreciation to our patients and their family for supporting us during this work. Finally, we should thank Mrs. Hagar Aboelfath Belal for her help in editing this manuscript.

\section{Authors' contributions}

All authors have participated inn in designing of the study, acquisition of data, data interpretation, and revising. HA recruited the patient and carried out clinical, neurological evaluation, and editing the manuscript. AA recruited the patient and carried out clinical, neurological evaluation, and editing the manuscript. OR recruited the patient and carried out clinical, neurological evaluation, participated in interpretation of the study results, and editing the manuscript. MA carried out laboratory investigation. ET recruited patient and carried out clinical, neurological evaluation, and participated in interpretation of the study results.

\section{Funding}

This research did not receive any specific grant from funding agencies in the public, commercial, or not-for-profit sectors.

\section{Availability of data and materials}

All raw data will be available on the editor request.

\section{Ethics approval and consent to participate}

The study protocol was approved by the ethical committee in Tanta University, Egypt, under the code number (3226/04/18) on April 2018. Participation was voluntary and all contributors received detailed information about the aims of this research work and an informed written consent was obtained prior to the commencement of the study.

Consent for publication

Not applicable

\section{Competing interests}

The authors have no conflict of interest to disclose.

\section{Author details}

${ }^{1}$ Neurology Department, Tanta University, Tanta 31527, Egypt. ${ }^{2}$ Clinical Pathology Department, Tanta University, Tanta, Egypt.

Received: 26 March 2020 Accepted: 6 July 2020

Published online: 16 July 2020

\section{References}

1. Waubant E, Lucas R, Mowry E, Graves J, Olsson T, Alfredsson L, et al. Environmental and genetic risk factors for MS: an integrated review. Ann Clin Transl Neurol. 2019:6(9):1905-22.

2. Shuster EA. Hormonal influences in multiple sclerosis. In Advances in multiple Sclerosis and Experimental Demyelinating Diseases. Springer, Berlin Heidelberg. 2008 (pp. 267-311)

3. Ysrraelit MC, Correale J. Impact of sex hormones on immune function and multiple sclerosis development. Immunology. 2019;156(1):9-22.

4. Confavreux C, Hutchinson M, Hours MM, Cortinovis-Tourniaire P, Moreau T. Pregnancy in Multiple Sclerosis Group. Rate of pregnancy-related relapse in multiple sclerosis. N Engl J Med. 1998;339(5):285-91.

5. Borba W, Zandman-Goddard G, Shoenfeld Y. Prolactin and autoimmunity: the hormone as an inflammatory cytokine. Best Pract Res Clin Endocrinol Metab. 2019;11:101324

6. Friedrichsen S, Harper CV, Semprini S, Wilding M, Adamson AD, Spiller DG, et al. Tumor necrosis factor-a activates the human prolactin gene promoter via nuclear factor-kB signaling. Endocrinology. 2006;147(2):773-81.

7. Wei W, Liu L, Cheng ZL, Hu B. Increased plasma/serum levels of prolactin in multiple sclerosis: a meta-analysis. Postgrad Med. 2017;129(6):605-10.

8. Shelly S, Boaz M, Orbach H. Prolactin and autoimmunity. Autoimmun Rev. 2012;11(6-7):A465-70.

9. Borba W, Shoenfeld Y. Prolactin, autoimmunity, and motherhood: when should women avoid breastfeeding? Clin Rheumatol. 2019;1:1-8.

10. Jara LJ, Medina G, Saavedra MA, Vera-Lastra O, Navarro C. Prolactin and autoimmunity. Clin Rev Allergy Immunol. 2011;40(1):50-9.

11. Ribeiro CM, Oliveira SR, Alfieri DF, Flauzino T, Kaimen-Maciel DR, Maes M, et al. Tumor necrosis factor alpha (TNF-a) and its soluble receptors are associated with disability, disability progression and clinical forms of multiple sclerosis. Inflamm Res. 2019;68(12):1049-59.

12. Thompson AJ, Banwell BL, Barkhof F, Carroll WM, Coetzee T, Comi G, et al. Diagnosis of multiple sclerosis: 2017 revisions of the McDonald criteria. Lancet Neurol. 2018;17(2):162-73.

13. Kurtzke JF. Rating neurologic impairment in multiple sclerosis: an expanded disability status scale (EDSS). Neurol. 1983;33(11):1444-52.

14. Giovannoni G, Cook S, Rammohan K, Rieckmann P, Sørensen PS, Vermersch $P$, et al. CLARITY Study Group. Sustained disease-activity-free status in patients with relapsing-remitting multiple sclerosis treated with cladribine tablets in the CLARITY study: a post-hoc and subgroup analysis. Lancet Neurol. 2011;10(4):329-37. 
15. Zych-Twardowska E, Wajgt A. Serum prolactin and sex hormone concentrations in patients with multiple sclerosis. Med Sci Monit. 1999:5(2): CR216-20.

16. De Giglio L, Marinelli F, Prosperini L, Contessa GM, Gurreri F, Piattella MC, et al. Relationship between prolactin plasma levels and white matter volume in women with multiple sclerosis. Mediat Inflamm. 2015;2015.

17. Pereira WL, Flauzino T, Alfieri DF, Oliveira SR, Kallaur AP, Lozovoy MA, et al. Prolactin is not associated with disability and clinical forms in patients with multiple sclerosis. NeuroMolecular Med. 2020;22(1):73-80.

18. Kallaur AP, Oliveira SR, Delicato de Almeida ER, Kaminami Morimoto H, Lopes J, de Carvalho Jennings Pereira WL, et al. Cytokine profile in relapsing-remitting multiple sclerosis patients and the association between progression and activity of the disease. Mol Med Rep. 2013;7(3):1010-20.

19. Rossi S, Motta C, Studer V, Barbieri F, Buttari F, Bergami A, et al. Tumor necrosis factor is elevated in progressive multiple sclerosis and causes excitotoxic neurodegeneration. Mult Scler J. 2014;20(3):304-12.

20. Belal T, El-Mitwalli A, El-Diasty A, El Mongui A. Serum prolactin level in patients with multiple sclerosis. Egypt J Neurol Psychiatr Neurosurg. 2015;1:52(2).

21. Grinsted L, Heltberg A, Hagen C, Djursing H. Serum sex hormone and gonadotropin concentrations in premenopausal women with multiple sclerosis. J Interdiscip Med. 1989;226(4):241-4.

22. Awerbuch Al, Sandyk R. Prolactin secretion in multiple sclerosis. Int J Neurosci. 1991;61(1-2):145-8.

23. Yamasaki K, Horiuchi I, Minohara M, Osoegawa M, Kawano Y, Ohyagi Y, et al. Hyperprolactinemia in optico-spinal multiple sclerosis. Intern Med. 2000; 39(4):296-9.

24. Markianos M, Koutsis G, Evangelopoulos ME, Mandellos D, Sfagos C. Serum and cerebrospinal fluid prolactin levels in male and female patients with clinically-isolated syndrome or relapsing- remitting multiple sclerosis. J Neuroendocrinol. 2010;22(6):503-8.

25. Correale J, Farez MF, Ysrraelit MC. Role of prolactin in B cell regulation in multiple sclerosis. J Neuroimmunol. 2014;269(1-2):76-86.

26. Gregg C. Pregnancy, prolactin and white matter regeneration. J Neurol Sci. 2009;285(1-2):22-7.

27. Koch MW, Liu WQ, Camara-Lemarroy C, Zhang Y, Pike GB, Metz L, et al. Domperidone-induced elevation of serum prolactin levels and immune response in multiple sclerosis. J Neuroimmunol. 2019:334:576974.

28. Kemanetzoglou E, Andreadou E. CNS demyelination with TNF-a blockers. Curr Neurol Neurosci Rep. 2017;17(4):36.

\section{Publisher's Note}

Springer Nature remains neutral with regard to jurisdictional claims in published maps and institutional affiliations.

\section{Submit your manuscript to a SpringerOpen ${ }^{\circ}$ journal and benefit from:}

- Convenient online submission

- Rigorous peer review

- Open access: articles freely available online

- High visibility within the field

- Retaining the copyright to your article

Submit your next manuscript at $\boldsymbol{\nabla}$ springeropen.com 